\title{
ATENÇÃO À SAÚDE E QUALIDADE DE VIDA DE PROFESSORES EM ENSINO REMOTO: RELATO DE EXPERIÊNCIA
}

\section{HEALTH CARE AND QUALITY OF LIFE OF PROFESSORS IN REMOTE EDUCATION: EXPERIENCE REPORT}

\author{
Susi Mary de Souza Fernandes* \\ ORCID: https://orcid.org/0000-0003-3826-6675 \\ Ana Paula Pimentel Costa** \\ ORCID: https://orcid.org/0000-0001-8650-8179 \\ Camila de Meirelles Landi*** \\ ORCID: https://orcid.org/0000-0002-8172-905X
}

Fernanda Barrinha Fernandes**** ORCID: https://orcid.org/0000-0002-7919-6098

Marcia Nacif Pinheiro***** ORCID: https://orcid.org/0000-0002-7885-3156

Sandra Ribeiro de Almeida Lopes****** ORCID: https://orcid.org/0000-0001-5186-4501

\section{Resumo}

A docência está entre as profissões de maior desgaste em saúde. A transição repentina para o ensino remoto durante a COVID-19 contribuiu para o aumento desses sintomas, gerando danos à qualidade de vida e bem-estar nesta população. Diante disto, o objetivo deste estudo é relatar a experiência do projeto extensionista de Atenção à Saúde do Professor em Ensino Remoto, realizado pelo QualiMack - Programa de Qualidade de Vida e Saúde no Trabalho, do Centro de Ciências Biológicas e da Saúde da Universidade Presbiteriana Mackenzie. Foram realizados encontros remotos baseados em Educação em Saúde, que consistiram em 8 encontros para Grupos de Orientação e 12, para Atividades de Relaxamento; criação e divulgação de peças autoinstrucionais de reforço. Participaram 176 docentes da instituição sede e 113 externos. As estratégias aumentaram o repertório em saúde dos participantes e contribuíram com a capacitação e aprimoramento da equipe no trabalho multidisciplinar e interação com a comunidade.

Palavras-chave: Relações Comunidade-Instituição; Educação a Distância; Educação em Saúde; Docentes; COVID-19

Data recebimento: 09/09/2021

Data de aceite: $11 / 11 / 2021$

\begin{abstract}
Teaching is amongst the most health damaging professions. The sudden transition to remote learning during the Covid19 pandemic contributed to an increase in these symptoms, reducing the quality of life and well-being of this population. Taking that into consideration, the aim of this study is to report the experience of the extension project of Health Care for Teachers in Remote Teaching, carried out by QualiMack - Quality of Life and Health at Work Program, of the Center for Biological and Health Sciences of the Mackenzie Presbyterian University. Remote meetings were held based on Health Education, which consisted of 08 meetings for Guidance Groups and 12 for Relaxation Activities. Some material summarizing the main content of the activities proposed was created and disseminated with the purpose of self-instructional reinforcement. A hundred and seventy-six professors from the host institution and 113 from other institutions participated. The strategies increased the participants' health repertoire and contributed to the training and improvement of the team in multidisciplinary work and interaction with the community.
\end{abstract}

Keywords: Community-Institutional Relations; Education, Distance; Health Education; Faculty; COVID-19.

* Professora da Universidade Presbiteriana Mackenzie (UPM), São Paulo - SP, Brasil. E-mail: susimary.fernandes@mackenzie.br ** Professora da Universidade Presbiteriana Mackenzie (UPM), São Paulo - SP, Brasil. E-mail: anapaula.costa@mackenzie.br *** Professora e Aluna de Doutorado da Universidade Presbiteriana Mackenzie (UPM), São Paulo - SP, Brasil. E-mail: camila.landi@mackenzie.br **** Professora da Universidade Presbiteriana Mackenzie (UPM), São Paulo - SP, Brasil. E-mail: fernanda.fernandes@mackenzie.br ***** Professora da Universidade Presbiteriana Mackenzie (UPM), São Paulo - SP, Brasil. E-mail: marcia.nacif@mackenzie.br ****** Professora da Universidade Presbiteriana Mackenzie (UPM), São Paulo - SP, Brasil. E-mail: sandra.lopes@mackenzie.br 


\section{Introdução}

O trabalho ocupa o centro da vida humana, tornando possível a transformação da realidade, viabilização da sobrevivência e formação da identidade. Por meio da atividade profissional o ser humano se expressa e se integra à sociedade. Nesse sentido, as pessoas dedicam a maior parte das suas vidas para consecução desse objetivo (DALAGASPERINA; MONTEIRO, 2016; DEJOURS, 1992).

Dentre as profissões formais no Brasil, a docência se encontra entre aquelas que apresentam os maiores índices de desgaste de saúde para os trabalhadores (DUMITH, 2020; XAVIER; MORAIS, 2007; PENTEADO; PEREIRA, 2007). Diante desse panorama, que não diz respeito apenas à realidade brasileira, pesquisas nacionais e internacionais têm demonstrado que as condições adversas da profissão afetam significativamente os índices de bem-estar psicológico e a qualidade de vida dos professores (PENTEADO; PEREIRA, 2007; XAVIER; MORAIS, 2007).

A pandemia causada pela COVID-19, desde março de 2020, desencadeou uma série de medidas preventivas no sentido de reduzir a transmissão e retardar a propagação do vírus, visto que naquele momento não havia evidências científicas claras para o tratamento medicamentoso específico e nem vacinas. Todavia, ao passo que essas ações visam a proteção da saúde física, por outro lado podem representar danos colaterais (VIEIRA et al., 2020).

O distanciamento social se destaca entre essas medidas preventivas, com o objetivo de diminuir a interação entre pessoas em uma comunidade. Uma estratégia necessária para que indivíduos já infectados e os assintomáticos, ainda não identificados, possam evitar a circulação e consequente disseminação do vírus (WILDER-SMITH; FREEDMAN, 2020).

As instituições de ensino foram as primeiras a cumprirem essas determinações (SARAIVA; TRAVERSINI; LOCKMANNK, 2020). Embora o processo de transferência da aprendizagem para um formato remoto ou online já fosse adotado em muitas instituições de ensino, as condições associadas à pandemia contribuíram para afetar todas as partes no processo de educação mundial, em especial a qualidade de vida dos docentes (SANTOS; SILVA; BELMONTE, 2021).

A transição emergencial para o ensino remoto alterou a rotina docente, impondo: adap-tação e domínio das tecnologias, preocupação com o desempenho dos alunos, exigências das instituições, associadas à pressão psicológica e fatores organizacionais. Essa associação de fatores gerou desconforto, sobrecarga e insegurança aos docentes, o que contribuiu para o aumento dos níveis de estresse e exaustão física e mental (MARTINS et al., 2021).

Em adição, o período de distanciamento social tem apresentado repercussões bastante significativas relacionadas ao comportamento sedentário. Estima-se que bilhões de pessoas em todo o mundo estejam inativas, com o aumento das horas na posição sentada e utilizando dispositivos eletrônicos como televisão, smartphones e computadores (MATIAS; DOMINSKI; MARKS, 2020), condição peculiar ao trabalho docente. 
Em estudo recente com a população brasileira maior de 18 anos, observou-se que mais de $50 \%$ dos homens e mulheres diminuíram os níveis de atividade física durante o isolamento social. Os autores inferem a necessidade de implementar medidas preventivas de saúde pública para apoiar a prática de atividades físicas em casa durante a pandemia (BOTERO et al., 2021).

Cientes das condições que esse momento impõe à vida dos docentes, tornou-se relevante propor um projeto designado Atenção à Saúde do Professor em Ensino Remoto, com início em agosto de 2020. O projeto é parte de um programa extensionista, de caráter interdisciplinar, desenvolvido desde 2010, com o objetivo de incentivar a melhoria na saúde e qualidade de vida dos trabalhadores e trabalhadoras (ABREU et al., 2014).

O papel da extensão universitária é promover a integração entre ensino, pesquisa e comunidade, mutuamente capaz de proporcionar aos discentes a vivência prática de conteúdos teóricos enquanto prestam assistência à sociedade (SANTOS; ROCHA; PASSAGLIO, 2016).

Uma ação que vise promover a saúde e melhorar a qualidade de vida no trabalho necessita auxiliar as pessoas a ponderar sobre a responsabilidade pessoal pela saúde e motivar a adoção de um estilo de vida que favoreça o bem-estar, tratando de temas globais que comsiderem os aspectos biológicos, psicológicos, sociais e espirituais do ser humano (ABREU et al., 2014).

Nesse sentido, o presente artigo tem como objetivo relatar a experiência de um projeto de extensão designado "Atenção à Saúde do Professor em Ensino Remoto", realizado pelo Centro de Ciências Biológicas e da Saúde da Universidade Presbiteriana Mackenzie.

\section{Metodologia}

Trata-se de um relato de experiência de um projeto extensionista, denominado "Atenção à Saúde do Professor em Ensino Remoto". O projeto foi concebido e integra as atividades do Programa de Extensão QualiMack - Programa de Qualidade de Vida e Saúde no Trabalho, que atende os preceitos éticos da Resolução $n^{\circ} 510$, de 07 de abril de 2016, do Conselho Nacional de Ética em Pesquisa (CONEP) declarados no artigo $1^{\circ}$, parágrafo único, item VIII.

O projeto teve início em agosto de 2020 e se encontra vigente, no entanto, o período retratado neste artigo se refere ao primeiro semestre de 2021. Inicialmente, foi realizado em parceria com a Pró-Reitoria de Ensino e Graduação e dedicado aos docentes do ensino superior da universidade sede ao longo do semestre letivo, não sendo, portanto, realizado no período de recesso escolar. 
Com apoio das mídias sociais, a partir do primeiro semestre de 2021 se expandiu, atingindo a comunidade externa. As atividades propostas aconteceram de modo remoto e síncrono em virtude das normas sanitárias vigentes e foram realizadas pela plataforma Zoom Meetings, com transmissão no Canal do YouTube.

Estiveram apoiados em três áreas de atuação, a saber: a) Grupos de Orientação (Palestras Educativas e Rodas de Conversa); b) Atividades de Relaxamento com Fisioterapia; c) Criação e divulgação de peças de reforço das orientações disponibilizadas em aplicativos de mensagens e nas redes sociais.

\section{Procedimentos}

Como parte do QualiMack - Programa de Qualidade de Vida e Saúde no Trabalho, as ações foram programadas em reunião de equipe, com a participação de docentes e discentes membros do programa.

O projeto é multidisciplinar e, portanto, participam um docente responsável de cada um dos cursos do Centro de Ciências Biológicas e da Saúde da universidade sede, a saber: Ciências Biológicas, Farmácia, Fisioterapia, Nutrição, Tecnologia em Gastronomia e Psicologia. Os discentes participantes são integrados ao programa por meio de processo seletivo próprio de cada curso e distribuídos nas ações alinhados com afinidades individuais e áreas temáticas.

A equipe se reúne para consolidação do projeto, na qual são decididas as metas e atribuições precedidas de ampla revisão de literatura, para que as ações tenham respaldo de evidências científicas.

A programação é divulgada por correio eletrônico e nas mídias sociais do programa. Os participantes se inscrevem preenchendo um formulário na plataforma Google Docs, elaborado pelo grupo, dividido em duas partes. A primeira parte consiste em Rastreio Sociodemográfico, que contempla duas seções: I - Dados pessoais e sociodemográficos, tais como identificação, idade, gênero, peso, altura, contato telefônico; II - Condição de Saúde: presença de doenças, de dor e desconforto músculo esquelético nas regiões corporais, uso de medicamentos, autopercepção da saúde e prática de atividade física.

A participação é voluntária e essa etapa tem o objetivo de conhecer o perfil de saúde para enquadrar o participante na atividade mais adequada e segura. Após enquadrado em uma das ações do projeto, é formado um grupo de comunicação via aplicativo de mensagens, para disponibilizar o link dos encontros remotos, material de reforço das orientações e manter um 
canal de comunicação para esclarecimento de dúvidas entre os participantes e a equipe do projeto. O participante pode se enquadrar no Grupo de Orientação, Atividade de Relaxamento com Fisioterapia e/ou nas duas atividades. Já para a comunidade externa, a participação é exclusivamente pelo acompanhamento do Grupo de Orientação na plataforma do YouTube.

Os Grupos de Orientação consistem em rodas de conversa síncronas na plataforma Zoom Meeting, com transmissão pelo YouTube, conforme ilustrado na Figura 1. A temática foi desenvolvida com o objetivo de discutir e trocar experiências, dentro das possibilidades individuais, temas voltados às mudanças de comportamento e impactos sobre o bem-estar e saúde durante a pandemia. Foram programados encontros com frequência de duas vezes por mês e duração de 1 minuto. Nos encontros, com a participação de toda a equipe, um professor membro do grupo apresenta a temática estabelecida e abre espaço para discussão.

Figura 1 - Temáticas abordadas nos Grupos de Orientação para docentes do ensino superior disponibilizados no Canal do YouTube.



Fonte: Printscreen Canal YouTube

A atividade fisioterapêutica de relaxamento consiste em encontros remotos em grupo, com frequência de 1 vez por semana e duração de 1 hora, para realizar exercícios de alongamento, fortalecimento, relaxamento muscular voltados para alívio das tensões do dia a dia e receber orientações ergonômicas sobre adaptações para o teletrabalho. Na plataforma Zoom Meeting, os participantes são orientados e acompanhados por discentes e docentes do curso de Fisioterapia, conforme ilustrado na Figura 2. 
Figura 2 - Atividade de relaxamento fisioterapêutico por teleatendimento

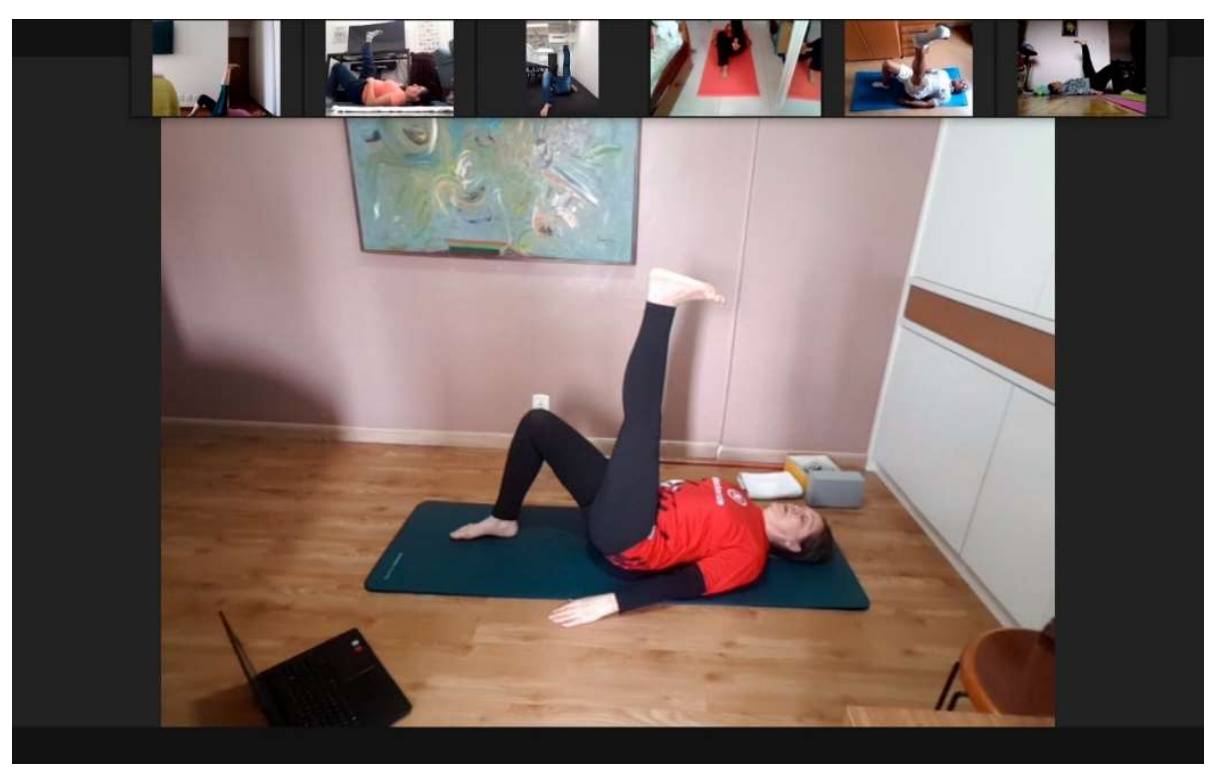

Fonte: Acervo pessoal

Por fim, para cada uma das atividades propostas, foram criadas peças de orientação autoinstrucional disponibilizadas nas redes sociais e nos grupos de mensagem como reforço das atividades desenvolvidas.

Para avaliar a aderência, foram coletados dados de frequência e acesso aos materiais autoinstrucionais. Além disso, os dados de rastreio sociodemográfico e condições de saúde foram registrados no início e no final do semestre, com o objetivo de subsidiar estudos futuros.

\section{Resultados}

Considerando todas as atividades propostas, participaram do projeto 172 docentes do ensino superior da universidade sede, com idade média de $51,4( \pm 7,4)$ anos, dos quais $77 \%$ do sexo feminino e $23 \%$ do sexo masculino. O controle de participação da comunidade externa se deu por meio de métricas disponibilizadas pelas plataformas sociais, como por exemplo número de visualizações dos conteúdos, conforme sumarizado na Tabela 1, a seguir. 
Tabela 1 - Número de visualizações dos Grupos de Orientação no Canal do YouTube por atividade entre março e maio de 2021, em ordem decrescente para o número de acessos.

\begin{tabular}{|c|c|}
\hline Tema & Número de Visualizações \\
\hline Higiene do Sono: Dicas para dormir melhor & 113 \\
\hline Acolha sua voz: ela diz muito sobre você & 107 \\
\hline Óleos essenciais para dormir melhor & 91 \\
\hline Sono e Alimentação como aliados na qualidade de vida & 48 \\
\hline Comensalidade: o resgate do convívio gastronômico & 46 \\
\hline
\end{tabular}

Fonte: Os autores

Os Grupos de Orientação foram consolidados em 8 encontros, nos meses de março a maio de 2021. O primeiro encontro foi realizado para explicar os objetivos e a organização do projeto e, no segundo, iniciamos com os Cuidados com a Saúde Mental - ambos aconteceram na Plataforma Zoom, sem transmissão no Canal do Youtube. A partir do terceiro encontro, iniciamos a transmissão ao vivo, com o cuidado de reforçar a cada transmissão o que havia sido abordado no tema anterior.

Os temas foram elencados considerando os principais problemas desenvolvidos a partir do distanciamento social, como saúde mental, sedentarismo, insônia e as repercussões sobre qualidade de vida e bem-estar. Nesta perspectiva, buscou-se não apenas transmitir informações sobre os impactos negativos, mas também apresentar possibilidades que aumentem o repertório dos participantes e motivem a adoção de um estilo de vida que favoreça o bemestar (FERREIRA et al., 2014; ABREU et al., 2014).

Para tanto, foram utilizadas estratégias baseadas na Educação em Saúde (ES) como meio de estimular hábitos saudáveis (FERREIRA et al., 2014). A interação promovida pela estratégia de ES entre uma equipe de profissionais e a comunidade propicia ao sujeito a oportunidade de realizar escolhas de acordo com seus propósitos e possibilidades e, ainda, habilita esses indivíduos para se atentarem ao progresso do seu nível de saúde (LIMA et al., 2019; FALKENBERG et al., 2014).

A adoção de hábitos e a criação de ambientes saudáveis são comportamentos fundamentais para que as pessoas alcancem um nível adequado de saúde. De tal modo que se tornem capazes de saber identificar os riscos e adotar novas atitudes, com autonomia e iniciativa própria, para utilizar as formas e os meios que dispõem para preservar e melhorar a própria vida (SANTANA et al., 2020; FALKENBERG et al., 2014). 
A ES é o instrumento nesse processo de conscientização individual e coletiva de responsabilidades e direitos à saúde, uma vez que medidas imperativas não são capazes de promover mudanças de comportamento duradouras (SANTANA et al., 2020; FERREIRA et al., 2014). Por meio de práticas pedagógicas transdisciplinares, a ES busca conhecer, sensibilizar, conscientizar, mobilizar e promover a coparticipação das pessoas e, deste modo, aumentar a capacidade de respostas para o enfrentamento de situações individuais e coletivas que interferem na manutenção da saúde e qualidade de vida (SANTANA et al., 2020; SALCI et al., 2013; ALVES; AERTS, 2011).

As Rodas de Conversa possibilitam o encontro e o diálogo entre os participantes, com a perspectiva de ressignificar sentidos e saberes. Nessa estratégia, os participantes têm o direito garantido de apropriação sobre um espaço para todo e qualquer diálogo e, assim, realizar análise crítica da realidade para alcançar o protagonismo de suas ações (SAMPAIO et al., 2014; FALKENBERG et al., 2014).

No primeiro encontro conduzido pela psicologia, o tema abordado foi: "Vivendo em distanciamento social - o que perdemos na pandemia? O que o isolamento nos ensinou?" Neste encontro, discutiu-se com os participantes sobre o estresse no trabalho e situações peculiares ao longo da vida, com o objetivo de demonstrar que tal condição não se caracteriza como algo exclusivo do momento de pandemia. No entanto, a necessidade de se adaptar rápidamente ao novo contexto do ensino remoto, somada à insegurança, ansiedade e demais apreensões, naturalmente desencadeadas pela pandemia, pode contribuir para alterações na saúde emocional. Diante disso, em uma roda de conversa foram discutidos os meios de enfrentamento, como o desenvolvimento de recursos e estratégias para ajudar a lidar com os problemas e situações limites na perspectiva de garantir a saúde emocional na quarentena.

No segundo, a temática conduzida pela fisioterapia abordou a higiene do sono. Foi discutida a mudança nos hábitos de sono durante a pandemia e a relação com permanecer por mais tempo em casa e menor gasto energético. Os participantes receberam informações sobre aspectos fisiológicos e a importância do sono para a qualidade de vida. Além disso, foram compartilhadas atitudes individuais e mudanças no ambiente para promover uma noite de sono reparadora.

Por solicitação dos participantes, no terceiro encontro convidamos uma fonoaudióloga para falar sobre cuidados com a voz. O conteúdo apresentado possibilitou reflexões muito importantes acerca do trabalho do professor. A profissional convidada é especialista em educação e abordou a dificuldade de adaptação do ensino presencial para o remoto, enfatizando que mudanças didáticas precisavam ser realizadas. A profissional destacou o tempo de atenção dos alunos durante as aulas síncronas e a necessidade de inserir metodologias ativas aliadas a recursos tecnológicos, a por exemplo da gameficação.

No quarto encontro, associamos os conhecimentos da farmácia e das ciências biológicas sobre a utilização de práticas integrativas e complementares (PICs) aos benefícios para 
a saúde e bem-estar no convívio com plantas. Nesse encontro, o objetivo foi apresentar as PICs, como chás, óleos essenciais e a aromaterapia como recursos preventivos e terapêuticos, aliados às terapias convencionais, para obcontrole de sintomas como ansiedade, insônia e estresse intenso, bastante comuns durante o isolamento promovido pela pandemia. Em adição, os participantes receberam informações sobre as melhores espécies para cultivo em ambientes fechados e foram orientados sobre como produzir hortas verticais em ambiente doméstico.

Nos dois últimos encontros, foram abordadas a gastronomia e a nutrição como elementoschave na saúde e bem-estar durante a pandemia. Iniciou-se com a reflexão sobre um dos maiores desafios do século XXI: a retomada aos hábitos saudáveis. Nessa perspectiva, foi discutido com os participantes como o distanciamento social produzido pela pandemia trouxe a possibilidade de repensar a alimentação e a gastronomia: "Qual era nossa relação com a comida e práticas culinárias, como era feita nossa lista de compras, nossas escolhas alimentares e nossas refeições. Será que tínhamos habilidades culinárias ou tempo para cozinhar nosso próprio alimento e para realizar as refeições com nossa família?". E assim, apresentar de uma maneira positiva como os momentos "gastronômicos e alimentares" mudaram.

No ambiente doméstico, passamos a aproveitar melhor o momento da refeição, criando alternativas e experiências. Novos hábitos, novas escolhas e partilhando o alimento com nossos familiares, em um ato genuíno de comensalidade (hábito de realizar refeições em conjunto, dividindo o alimento com o grupo, socializando e ritualizando a refeição). Nesse sentido, com-cluir com o grupo que essa é uma tendência, que havia se perdido e a pandemia fez ressurgir.

Em complemento, discutiram-se as informações veiculadas na mídia acerca da alimentação e prevenção da COVID-19, com o objetivo de orientar o efeito de uma dieta balanceada para fortalecer o sistema imunológico e melhorar a saúde geral. Destacam-se alguns nutrientes com importante papel imunológico ao nosso organismo e onde encontrá-los, além de abordar a necessidade de higiene dos alimentos em tempos de pandemia.

Todos os envolvidos nesse projeto, docentes e discentes organizadores e o público-alvo, estiveram expostos aos desafios impostos pela pandemia. Os organizadores eram da área da saúde da universidade sede, os participantes eram docentes de outras áreas do saber da universidade sede e de diversas universidades. Embora em situações distintas, todos apresentavam um objetivo comum: a manutenção da saúde e qualidade de vida durante o distanciamento social.

Nesse sentido, com a proposta baseada em orientações de saúde, seguida de roda de conversa, buscou-se, por meio da troca de experiências, refletir sobre esse objetivo e encontrar meios para atuar no enfrentamento e na valorização do que realmente importa. Em todos os encontros, os participantes realizam perguntas e/ou expõem sua opinião por comentários no chat, que são lidos pelo moderador e, em seguida, debatidos com o grupo.

A atividade de relaxamento com Fisioterapia foi realizada por meio de teleatendimento - uma modalidade de atenção remota, com grande repercussão durante o distan-cia- 
mento social promovido pela pandemia, que permite a continuidade de cuidados de saúde na segurança do ambiente doméstico. Segundo Matias et al. (2020), além de todos os efeitos da prática de exercício regular, nesse momento, a atividade realizada em domicílio e controlada de modo virtual promove conexões sociais e virtuais que aumentam os sentimentos de autonomia e de bem-estar com a vida.

Foram realizados 12 encontros no primeiro semestre de 2021 (março a maio), com frequência de uma vez por semana, comandados por dois docentes e acompanhados por quatro discentes do curso de Fisioterapia. Os docentes eram responsáveis por orientar os exercícios e os discentes monitoravam os participantes durante a execução das atividades propostas. Os encontros foram realizados pela plataforma Zoom Meeting e os participantes recebiam, no grupo de mensagem, orientações sobre material, roupas necessárias e posicionamento da câmera do notebook, computador ou celular para facilitar o acompanhamento e as correções durante a execução das atividades, conforme ilustrado na Figura 3.

Figura 3 - Material utoinstrucional com orientações para o teleatendimento: (a) orientações para uso de celular. Os materiais podem ser acessados no Instagram ou Facebook do Programa.

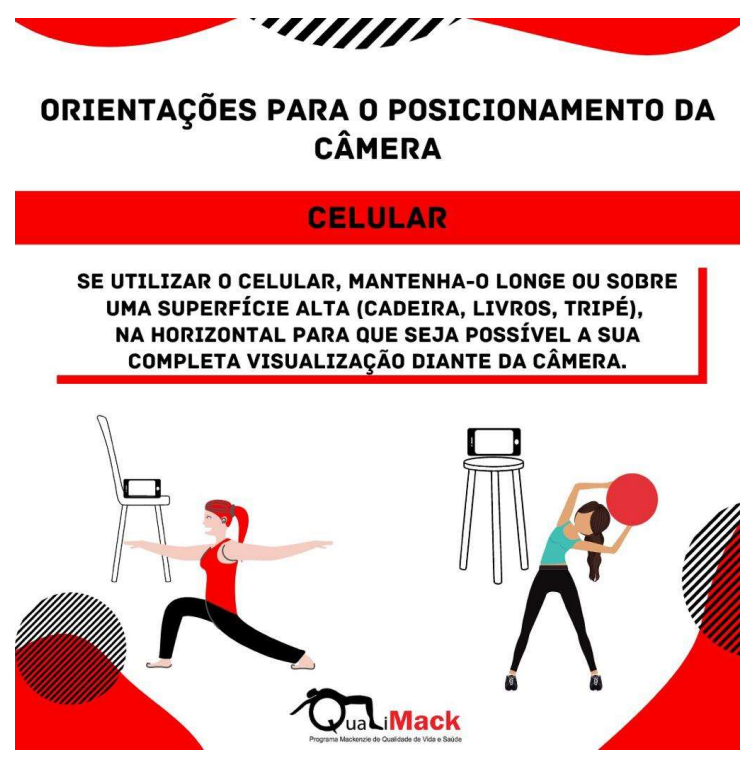

Fonte: Acervo pessoal

As atividades foram baseadas em liberação miofascial (LMF), técnica terapêutica que tem como objetivo mobilizar a fáscia muscular por meio de recursos manuais, aparelhos ou movimentos específicos para diminuir a tensão por estresse mecânico e aumentar a flexibilidade (SILVA et al., 2017; AJIMSHA, 2011). 
Para essa atividade, os participantes responderam ao questionário sobre presença de sintomas, como dor e desconforto músculo esquelético relacionados ao trabalho, antes da primeira intervenção e após a intervenção no final. Esses dados foram coletados com o objetivo de elaborar atividades que priorizassem o relaxamento das regiões mais acometidas e, ainda, realizar orientações sobre aspectos ergonômicos relacionados ao posto de trabalho adaptado para o domicílio que pudessem influenciar os sintomas relatados. Ao final das intervenções, notou-se uma diminuição importante dos relatos de dor e desconforto para todas as regiões avaliadas.

As queixas relatadas pelos docentes estão relacionadas ao estresse ocupacional promovido pela atividade de trabalho e, portanto, a remissão completa dos sintomas depende do conjunto de condições que envolvem o trabalho docente, como adequação do ambiente ergonômico, adaptação e domínio das tecnologias, preocupação com o desempenho dos alunos, fatores psicológicos e organizacionais (SANTOS; SILVA; BELMONTE, 2021).

Deste modo, como meio para reforçar as conclusões do grupo e favorecer a mudança de hábito, foram criadas e divulgadas peças de orientação com os principais conteúdos tratados em todas as atividades propostas. Elas foram disponibilizadas nas redes sociais do programa e/ou enviadas nos grupos do aplicativo de mensagem, conforme ilustrado na Figura 4.

Figura 4 - Material autoinstrucional como reforço da palestra de saúde mental disponibilizado nos grupos de mensagens e nas redes sociais, em formato carrossel: (4a - página 1; 4b - página 2).

Os materiais podem ser acessados no Instagram ou Facebook do Programa.

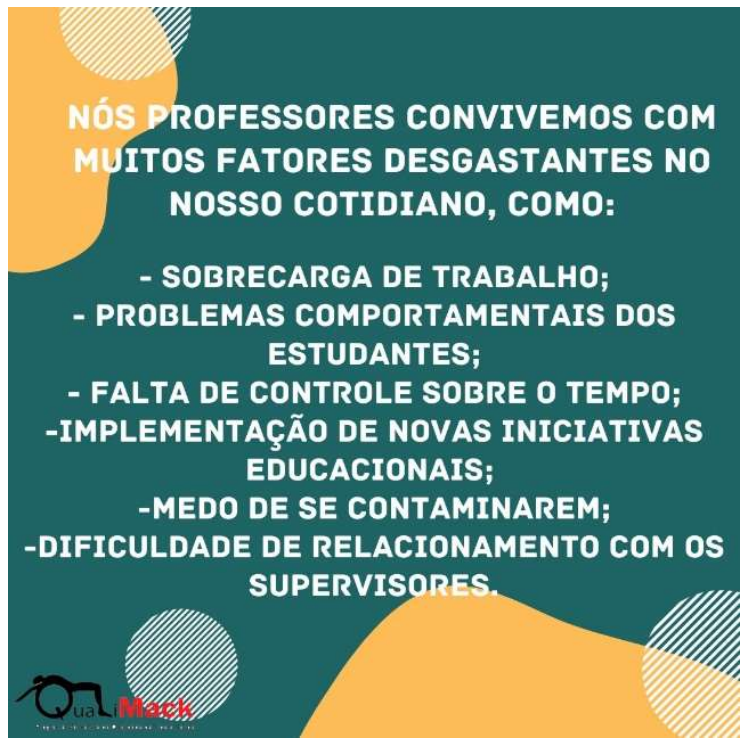

(4a)

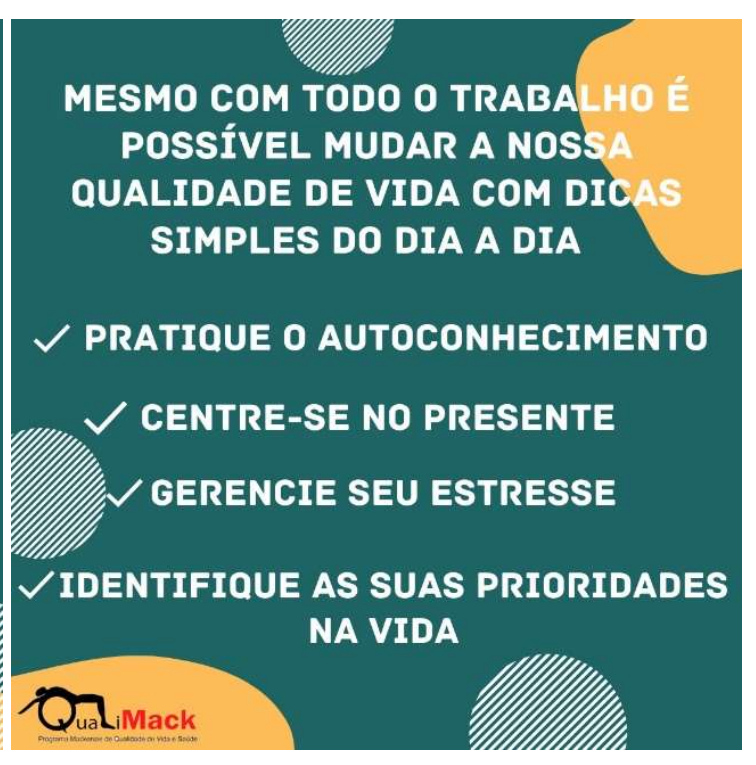

(4b)

Fonte: Acervo pessoal 
Os resultados alcançados com o projeto foram promissores, notados na participação das atividades síncronas e nas métricas de visualização dos conteúdos disponibilizadas pelas redes sociais (Tabela 1). Os conteúdos gravados no YouTube e as publicações nas redes sociais permitem que os participantes retomem os conteúdos e novas visualizações a qualquer tempo.

Isso amplia o alcance das informações e favorece a difusão do conhecimento produzido na universidade, ao mesmo tempo que aproxima o programa de novos participantes da comunidade externa. As tecnologias de informação e comunicação (TICs) aplicadas ao ensino têm oportunizado mudanças significativas na relação ensino-aprendizagem, embora não substituam o modelo presencial (ALBON et al., 2020).

A participação de docentes e discentes de cursos de graduação na construção e o desenvolvimento de um projeto de extensão baseado em ações interdisciplinares favorecem a interação e o fortalecimento das relações - elementos fundamentais para o crescimento profissional e acadêmico, uma vez que propiciam experiências diferenciadas vivenciadas em cenário inovador de troca de saberes entre comunidade acadêmica e a sociedade (SANTOS; ROCHA; PASSAGLIO, 2016).

\section{Considerações finais}

Durante a pandemia, o home office assumiu enorme relevância na vida das pessoas, trabalhando-se muito, a despeito dos direitos ao descanso. O tempo livre foi invadido por mais dedicação ao trabalho, causando uma sensação de perda da vida privada e familiar. $\mathrm{O}$ projeto Atenção à Saúde do Professor em Ensino Remoto apresentou resultados satisfatórios ao aproximar os participantes para debates sobre as adversidades impostas por esse contexto completamente atípico. O diálogo com os pares favoreceu a percepção de significados comuns, que contribuíram para a construção de conhecimento e adoção de hábitos que favorecem o bem-estar.

A interação promovida pela metodologia baseada em ES oportunizou aos participantes compreender e desenvolver estratégias para lidar com as cobranças, medo, incertezas e expectativas do momento. Ao mesmo tempo, proporcionou à equipe capacitação e aprimoramento técnico pelo trabalho multidisciplinar diante de novas formas de interação com a comunidade. Deste modo, alcançando o papel da extensão universitária em promover a integração entre os conhecimentos técnico científicos com a comunidade.

Os resultados deste projeto possibilitaram uma análise crítica e reflexiva sobre a repercussão do nosso papel de educadores em saúde. A troca de experiências entre docentes e discentes, com pontos de vista de lugares diferentes, permitiu ao grupo perceber que não se 
trata apenas de domínio do conhecimento. Para a mudança de comportamento, é necessária uma abordagem criativa, colaborativa e contínua, que proporcione aos sujeitos um espaço para qualquer tipo de diálogo.

Cabe ressaltar que, embora as ferramentas digitais tenham nos permitido alcançar a comunidade externa, problemas com conectividade atrapalharam a participação mais efetiva em alguns momentos. Além disso, a rotina docente foi uma limitação importante para estabelecer um horário para realização das atividades.

Assim, sugerimos aos profissionais de saúde e às instituições de ensino a inserção de medidas de educação em saúde para docentes, com vistas à promoção de saúde e bem-estar, bem como a prevenção e o controle do adoecimento. Reforçamos, ainda, que a elaboração e aplicação de ES aconteçam de forma integrada entre instituições de ensino e em todos os níveis educacionais.

\section{Referências}

ABREU et al. Interdisciplinaridade, saúde e qualidade de vida no ambiente universitário: Relato de Experiência. Rev. Simbio-Logias, Botucatu, v.7, n. 10, p. 107-118, 2014. Disponível em: https://www.ibb.unesp.br/\#!/ensino/departamentos/educacao/revista-simbiologias/volume-7---numero-10--2014/. Acesso em: 21 ago. 2021.

AJIMSHA, M. S. Effectiveness of direct vs indirect technique myofascial release in the management of tension-type headache. Journal of Bodywork and Movement Therapies, v.15, n.4, p.431-435, 2011. DOI: 10.1016/j.jbmt.2011.01.021. Disponível em: https://doi.org/10.1016/j.jbmt.2011.01.021. Acesso em: 8 abr. 2021.

ALBON, S. P.; LARSON, K.; MARCHAND, J.P. Lecture capture in pharmacy education at UBC: Updating our understanding. Currents in Pharmacy Teaching and Learning, v. 12, n. 1, p. 1037-1045, 2020. DOI: 10.1016/j.cptl.2020.04.031. Disponível em: https://doi.org/10.1016/j.cptl.2020.04.031. Acesso em: 8 abr. 2021.

ALVES, G. G.; AERTS, D. As práticas educativas em saúde e a Estratégia Saúde da Família. Ciênc. saúde coletiva [online]. v.16, n.1, p.319-325, 2011. DOI. 10.1590/S141381232011000100034. Disponível em: https://doi.org/10.1590/S1413-81232011000100034. Acesso em: 3 mar. 2021. 
BOTERO et al. Impact of the COVID-19 pandemic stay at home order and social isolation on physical activity levels and sedentary behavior in Brazilian adults. Einstein, São Paulo, v.19, p.1-6, 2021. DOI: 10.31744/einstein_journal/2021AE6156. Disponível em: https://doi.org/10.31744/einstein_journal/2021AE6156. Acesso em: 22 maio 2021.

DEJOURS, C. A loucura do trabalho: estudo de psicopatologia do trabalho. São Paulo: Cortez-Oboré, 1992.

DALAGASPERINA, P.; MONTEIRO, J.K. Estresse e docência: um estudo no ensino superior privado. Rev Subjetividades, Fortaleza, v.16, n.1, p.37-51, 2016. DOI: 10.5020/23590777.16.1.37-51. Disponível em: https://doi.org/10.5020/23590777.16.1.3751. Acesso em: 7 mar. 2021.

DUMITH, S. C. Atividade física e qualidade de vida de professores universitários. Cad. saúde colet., v. 28, n.3, p. 438-446, 2020. DOI: 10.1590/1414-462X202028030593. Disponível em: https://doi.org/10.1590/1414-462X202028030593. Acesso em: 8 maio 2021.

FALKENBERG, M. B.; MENDES, T.P.L.; MORAES, E. P.; SOUZA, E.M. Educação em saúde e educação na saúde: conceitos e implicações para a saúde coletiva. Ciênc. saúde coletiva [online], v.19, n.3, p.847-852, 2014. DOI: 10.1590/1413-81232014193.01572013. Disponível em: http://dx.doi.org/10.1590/1413-81232014193.01572013. Acesso em: 3 mar. 2021.

FERREIRA, V. F. et al. Educação em saúde e cidadania: Revisão integrativa. Trab. Educ. Saúde, Rio de Janeiro, v. 12, n. 2, p. 363-378, 2014. DOI: 10.1590/S1981- 77462014 000200009. Disponível em: https://doi.org/10.1590/S1981-77462014000200009. Acesso em: 3 mar. 2021.

LIMA, G. C. B. B. et al. Educação em saúde e dispositivos metodológicos aplicados na assistência ao Diabetes Mellitus. Saúde Debate, Rio de Janeiro, v. 43, n. 120, p. 150-158, 2019. DOI: 10.1590/0103-1104201912011. Disponível em: https://doi.org/10.1590/01031104201912011. Acesso em: 8 maio 2021.

MARTINS, A. C. B. L. et al. A experiência de professores no ensino remoto: dilemas, saúde mental e contextos de trabalho na pandemia. Expressa Extensão, v. 26, n.2, 2021. DOI: 10.15210/ee.v26i2.20468. Disponível em: https://doi.org/10.15210/ee.v26i2.20468. Acesso em: 31 ago. 2021.

MATIAS, T.; DOMINSKI, F.H.; MARKS, D.F. Human needs in COVID-19 isolation. J Health Psychol., v.25, n.7, p.871-882, 2020. DOI: 10.1177/1359105320925149. Disponível em: https://doi.org/10.1177/1359105320925149. Acesso em: 8 mar. 2021. 
PENTEADO, R. Z.; PEREIRA, I.M.T.B. Qualidade de vida e saúde vocal de professores. Rev. Saúde Pública, v.41, n. 2, p. 236-243, 2007. DOI: 10.1590/S0034-89102007000200010. Disponível em: https://doi.org/10.1590/S0034-89102007000200010. Acesso em: 3 mar. 2021.

SALCI, M.A. et al. Educação em saúde e suas perspectivas teóricas: algumas reflexões. Texto contexto - enferm. [online]. v.22, n.1, p.224-230, 2013. DOI: 10.1590/S010407072013000100027. Disponível em: https://doi.org/10.1590/S0104-07072013000100027. Acesso em: 3 mar. 2021.

SAMPAIO, J.; SANTOS, G.C.; AGOSTINI, M.; SALVADOR, A.S. Limits and potentialities of the circles of conversation: analysis of an experience with young people in the backcountry of Pernambuco, Brazil. Interface, Botucatu. v. 18, p. 1299s-1312s, 2014, Supl 2. DOI: 10.1590/1807-57622013.0264. Disponível em: https://doi.org/10.1590/180757622013.0264. Acesso em: 8 maio 2021.

SANTANA, C.S. et al. Viver a arte em saúde: a contação de histórias como estratégia para a produção participativa de conhecimentos em promoção da saúde. Revista Ciências \& Ideias, Rio de Janeiro. v. 11, n.2, p.214-225, 2020. DOI: 10.22407/2176-1477/2020.v11 i2.1143. Disponível em: http://dx.doi.org/10.22407/2176-1477/2020.v11i2.1143. Acesso em: 8 maio 2021.

SANTOS, G. M. R. F.; SILVA, M. E.; BELMONTE, B. R. COVID-19: ensino remoto emergencial e saúde mental de docentes universitário. Rev. Bras. Saúde Matern. Infant., Recife, v. 21, p. s245-s251, 2021, Supl. 1. DOI: 10.1590/1806-9304202100S100013. Disponível em: http://dx.doi.org/10.1590/1806-9304202100S100013. Acesso em: 3 mar. 2021.

SANTOS, J. H. S.; ROCHA, B. F.; PASSAGLIO, K.T. Extensão Universitária e formação no Ensino Superior. Revista Brasileira de Extensão Universitária, v.7, n.1, p.23-28, 2016. DOI: 10.36661/2358-0399.2016v7i1.3087. Disponível em: https://doi.org/10.36661/23580399.2016v7i1.3087. Acesso em: 10 ago. 2021.

SARAIVA, K.; TRAVERSINI, C.; LOCKMANNK, A. Educação em tempos de COVID19: ensino remoto e exaustão docente. Prax Educ., Ponta Grossa, v. 15, p. 1-24. 2020. DOI: 10.5212/PraxEduc.v.15.16289.094. Disponível em: https://doi.org/10.5212/PraxEduc. v.15.16289.094. Acesso em: 12 abr. 2021.

SILVA, D.L. et al. Efeitos da Liberação Miofascial Sobre a Flexibilidade: uma Revisão Sistemática. J Health Sci., v. 19, n. 2, p. 200-4, 2017. DOI: 10.1016/j.jbmt.2015.08.007. Disponível em: https://doi.org/10.1016/j.jbmt.2015.08.007. Acesso em: 05 ago. 2021. 
VIEIRA, C.M. et al. COVID-19: the forgotten priorities of the pandemic. Maturitas, v. 136, p. 38-41, 2020. DOI: doi.org/10.1016/j.maturitas.2020.04.004. Disponível em: https://doi.org/10.1016/j.maturitas.2020.04.004. Acesso em: 5 ago. 2021.

WILDER-SMITH, A. E.; FREEDMAN, D. O. Isolation, quarantine, social distancing and community containment: pivotal role for old-style public health measures in the novel coronavirus (2019-ncov) outbreak. Journal of Travel Medicine, v. 27, n. 2, p. 20, 2020. DOI: $10.1093 / \mathrm{jtm} / \mathrm{taaa} 020$. Disponível em: https://doi.org/10.1093/jtm/taaa020. Acesso em: 3 abr. 2021.

XAVIER, C.E.S.; MORAIS, A.S. Qualidade de vida em professores da rede pública estadual de ensino da cidade de ARACAJU-SE. Rev Bras Prescrição e Fisiologia do Exercício, v. 1, n.5, p.85-94, 2007. Disponível em: http://www.rbpfex.com.br/ index.php/rbpfex/article/view/51. Acesso em: 7 mar. 2021. 